\title{
The Norm of Fundamental Movement Skills for Children Aged Three to Seven
}

\author{
Shu-Jung Lin ${ }^{1}$, Shu-Chu Yang, ${ }^{2, *}$ \\ ${ }^{1}$ Department of Early Childhood Education, Nanhua University, Taiwan \\ ${ }^{2}$ Department of Early Childhood Education, National Chiayi University, Taiwan,
}

Received June 8, 2020; Revised July 21, 2020; Accepted August 10, 2020

\section{Cite This Paper in the following Citation Styles}

(a): [1] Shu-Jung Lin, Shu-Chu Yang , "The Norm of Fundamental Movement Skills for Children Aged Three to Seven," International Journal of Human Movement and Sports Sciences, Vol. 8, No. 4, pp. 134 - 141, 2020. DOI: 10.13189/saj.2020.080405.

(b): Shu-Jung Lin, Shu-Chu Yang (2020). The Norm of Fundamental Movement Skills for Children Aged Three to Seven. International Journal of Human Movement and Sports Sciences, 8(4), 134 - 141. DOI: 10.13189/saj.2020.080405.

Copyright@2020 by authors, all rights reserved. Authors agree that this article remains permanently open access under the terms of the Creative Commons Attribution License 4.0 International License

\begin{abstract}
Childhood was the key period for the development of fundamental movement skills, the acquisition of which had a definite bearing on a child's overall development, including such areas as cognition, interpersonal relationships, social behavior, and environmental awareness. The main purpose of this study was on the development of the norm of fundamental movement skills for children aged three to seven. In the method, we measured the development of such skills amongst 1,029 children in Taiwan aged 3-7 using the Test of Gross Motor Development-2 (TGMD-2). The results indicated that the fundamental movement skills increase with age. With a percentile rank of 50 in the overall fundamental movement skills, the mean score of the eight age groups, boys performed better than girls in the seven age groups. In conclusion, compared to the United States, Taiwanese five through seven-year-olds lag far behind their American counterparts in locomotor and object control skills, and this situation needed to be addressed by education authorities in Taiwan. Based on the findings of this study, for preschool teachers, most are women with little or no training in FMS education. The curriculum of preschool teachers' training at the universities should incorporate FMS into the PE course, and it is important to ensure that each pre-service preschool teacher has the ability to design a series of 30-60 minutes of dynamic, age-appropriate and fun vigorous exercise.
\end{abstract}

Keywords Locomotor Skills, Object Control Skills, Percentile Rank

\section{Introduction}

In her forward to the Chinese translation of Spark: The Revolutionary New Science of Exercise and the Brain, Daisy L. Hung describes a ground-breaking physical education (PE) program called "Zero Hour PE," an optional class consisting of rigorous exercise scheduled before first period at a high school near Chicago, USA. After the program was in place for some time, testing revealed significant increases in the participants' levels of dopamine, serotonin, and norepinephrine, as well as corresponding increases in memory, concentration, and grades, clearly demonstrating that exercise has a direct impact on learning [1]. Similarly, Strong et al. [2] found that regular exercise has a positive impact on a child's body mass and mental health. Moreover, Shields [3] found that eight percent of Canadian children aged $2-5$ are overweight, and many other studies have found a connection between obesity and various types of chronic illness, including cardiovascular disease, and that overweight kids are more likely to suffer from low self-esteem [4-6]. Further, research on preschoolers by Williams et al. and Fisher et al. found that preschoolers with relatively better fundamental movement skills (FMS) are more willing to participate in sports activities, and also perform better in those activities; they also found that preschoolers with lower FMS levels tend to lack confidence when participating in sports $[7,8]$. Thus the development of FMSs amongst preschoolers is an important topic requiring in-depth study. 
Preschool and elementary school are the key periods for the development of FMSs and advanced movement skills [9-12], the acquisition of which has a strong bearing on a child's overall development, including such areas as physical fitness, cognition, emotional intelligence, interpersonal relationships, social behavior, and environmental awareness[13-15]. FMSs are also the foundation for the development of advanced movement skills and specialized athletic abilities [16,17].

Wrotnik, Epstein, Dorn, Jones, and Kondilis [18] found a positive correlation between the movement skills of school children and the frequency and duration of their exercise. Also, Oliver, Schofield, and McEvoy [19] suggest that school children should make a habit of exercising between 30 and 60 minutes daily, since doing so has a positive impact on both health and school work. Indeed, the FMSs acquired during preschool are essential in everyday life and for successful participation in elementary school PE classes and a wide variety of other activities [3]. In Taiwan, increasing importance is being given to PE at the preschool level, and 30 minutes per day of vigorous exercise has recently been added to the list of items for evaluating kindergartens; moreover, the acquisition of FMSs features prominently in the curriculum at most preschools. In sum, preschoolers' acquisition and development of FMSs needs to be given due attention, since they have such a strong bearing on a child's overall development, including such areas as physical and mental health, cognition, emotional intelligence, interpersonal relationships, social behavior, and environmental awareness.

Interestingly, Wang's literature review [20] found that Taiwanese preschoolers lag far behind their American counterparts, especially in object manipulation skills. However, in light of the lack of standardized tools for testing the FMSs of Taiwanese preschoolers, and the relative lack of related data, the actual situation remains unclear. As for previous studies conducted in Taiwan using the Test of Gross Motor Development-2 (TGMD-2) to measure the FMSs of schoolchildren, there has been one dissertation and two theses; the dissertation's sample covered a wide range of ages (from preschoolers up to third graders), but all the participants were in the Chiayi area [21]. As for the two theses, neither included preschoolers; Wang's aim was to set up standards for movement skills for a class of fourth graders [22], and Chen's aim was to set up standards for object manipulation skills for first-to-fourth graders at a particular elementary school [23]. In each of these three studies, it was found that Taiwanese children lag behind their American counterparts in locomotor and object manipulation skills and that boys are better than girls in object manipulation skills.

In light of the above, the purpose of the present study was to measure the FMSs of children in Taiwan aged 3-7 and to establish related norms.

\section{Materials and Methods}

\subsection{Participants}

The research participants were Taiwanese children aged $3-7$, all of whom were in good health. Purposive sampling was used to recruit a total of 1,200 participants, 300 each in the four regions into which Taiwan is customarily divided: north, center, south, and east (including the outlying islands). Prior to testing the participants' FMSs, their parents signed a consent form and filled out a form requesting the participants' basic information.

Amongst the 1,200 participants, 171 failed to participate in all the tests and were thus excluded from the results, leaving 1,029 (85.75\%) participants, 516 boys (50.1\%) and 513 girls (49.9\%). As for age, 104 (10.1\%) were between the ages of three and four, 331 (32.2\%) were between the ages of four and five, $357(34.7 \%)$ were between the ages of five and six, and 237 (23.0\%) were between the ages of six and seven. The average age of the participants was 61 months. As for body mass index (BMI), a total of 22 (2.1\%) were below normal weight; 710 (69\%) had a normal weight; and 297 (28.9\%) were overweight, as defined by Health Promotion Administration, Ministry of Health and Welfare [24] (Table 1). The participants' average height was 109.37 centimeters, their average weight was 19.87 kilograms, and their average BMI was 16.48.

Table 1. Taiwan's Ministry of Health and Welfare「The BMI of Child and adolescent 」

\begin{tabular}{|c|c|c|c|c|c|c|}
\hline \multirow{2}{*}{ age } & \multicolumn{4}{|c|}{ boy } & \multicolumn{2}{c|}{ girl } \\
\cline { 2 - 7 } & $\begin{array}{c}\text { underweight } \\
\text { BMI }<\end{array}$ & $\begin{array}{c}\text { normal } \\
\text { BMI 介於 }\end{array}$ & $\begin{array}{c}\text { Overweight } \\
\text { BMI } \geqq\end{array}$ & $\begin{array}{c}\text { underweight } \\
\text { BMI }<\end{array}$ & $\begin{array}{c}\text { normal } \\
\text { BMI 介於 }\end{array}$ & $\begin{array}{c}\text { Overweight } \\
\text { BMI }\end{array}$ \\
\hline 3 & 13.7 & $13.7-17.0$ & 17.0 & 13.5 & $13.5-16.9$ & 16.9 \\
\hline 3.5 & 13.6 & $13.6-16.8$ & 16.8 & 13.3 & $13.3-16.8$ & 16.8 \\
\hline 4 & 13.4 & $13.4-16.7$ & 16.7 & 13.2 & $13.2-16.8$ & 16.8 \\
\hline 4.5 & 13.3 & $13.3-16.7$ & 16.7 & 13.1 & $13.1-16.9$ & 16.9 \\
\hline 5 & 13.3 & $13.3-16.7$ & 16.7 & 13.1 & $13.1-17.0$ & 17.0 \\
\hline 5.5 & 13.4 & $13.4-16.7$ & 16.7 & 13.1 & $13.1-17.0$ & 17.0 \\
\hline 6 & 13.5 & $13.5-16.9$ & 16.9 & 13.1 & $13.1-17.2$ & 17.2 \\
\hline 6.5 & 13.6 & $13.6-17.3$ & 17.3 & 13.2 & $13.2-17.5$ & 17.5 \\
\hline
\end{tabular}




\subsection{Research Tools}

The main testing tool used in this study was the TGMD-2, a widely used test developed in the US by Ulrich and Sanford [12] (2000). There were three main reasons for selecting the TGMD-2. First, the TGMD-2 is designed for testing children between the ages of three and ten in a period of between 15 and 20 minutes and includes locomotor skills (run, gallop, hop, leap, horizontal jump, slide) and object control skills (striking a stationary ball, stationary dribble, kick, catch, overhand throw, and underhand roll). Second, the TGMD-2 has a high degree of reliability and validity $\left(\mathrm{x}^{2}=280.3\right.$; $\mathrm{GFI}=.96$; $\left.\mathrm{AGFI}=.95\right)$ in terms of internal consistency, test-retest reliability, and inter-rater reliability (between .85 and .98). Third, while testing the FMSs of children in Hong Kong, Wong and Cheung [25] found the confirmatory factor analysis (CFA) of the TGMD-2 to be quite suitable, thereby demonstrating that it is also suitable for use in Chinese cultures such as Taiwan.

\subsection{Procedures}

Individual testing was conducted in each of the four regions by graduate students and university seniors studying physical education and early childhood education. All of the testing personnel had a strong interest in the topic of study and adequate time to participate and had already completed a university or graduate school course in sports and physical skills. Three training sessions were provided to all of the testing personnel, and each session included instruction and practice in how to use the testing equipment, the testing methods to be used, setting up the testing area, watching a demonstration video produced by the researchers, running practice drills, and a discussion of the problems most commonly encountered during testing. Prior to the actual testing, the testers were required to demonstrate their ability to carry out the testing procedures in a satisfactory manner.

The testing was carried out at each participating preschool over one or two days. Using each preschool's outdoor playground, the testers set up a video camera and prepared the testing equipment: an 8"-10" plastic playground or soccer ball, a 4 " plastic ball, a tennis ball, a 4"-5" square bean bag, two traffic cones, colored tape, a plastic baseball bat, a nerf ball, and a batting tee. The testing was conducted on a level and uncluttered surface in good weather during daylight hours, at a time when there was little noise or other distractions.

\subsection{Data Analysis}

The Statistical Package for the Social Sciences (SPSS) for Windows, version 22.0, was used to compile the data and to calculate the means, standard deviations, standard scores, and percentages, all of which were used to analyze the participants' FMSs and to calculate the norms for the locomotor skills, object control skills, and overall FMSs.

\section{Results}

\subsection{The FMSs}

The participants were divided into four age groups: $3-4$, 4-5, 5-6, and 6-7. As shown in Table 2, respectively for each age group, the mean scores in locomotor skills were 18.00, 20.76, 23.64, and 24.17; the mean scores in object control skills were 17.22, 19.44, 22.58, and 24.41; and the mean scores for overall FMSs were 35.22, 40.20, 46.23, and 48.57 (Table 2).

Table 2. Status of development of FMSs

\begin{tabular}{|c|c|c|c|c|}
\hline \multirow{2}{*}{ Item } & \multirow{2}{*}{ age } & \multicolumn{3}{|c|}{$\mathrm{N}=1029$} \\
\hline & & $\mathrm{N}$ & $M$ & SD \\
\hline \multirow{5}{*}{$\begin{array}{l}\text { locomotor } \\
\text { skills }\end{array}$} & $3 \sim 4$ & 104 & 18.00 & 5.98 \\
\hline & $4 \sim 5$ & 331 & 20.76 & 5.70 \\
\hline & $5 \sim 6$ & 357 & 23.64 & 5.45 \\
\hline & $6 \sim 7$ & 237 & 24.17 & 5.23 \\
\hline & Total & 1029 & 22.27 & 5.89 \\
\hline \multirow{5}{*}{$\begin{array}{l}\text { object control } \\
\text { skills }\end{array}$} & $3 \sim 4$ & 104 & 17.22 & 4.50 \\
\hline & $4 \sim 5$ & 331 & 19.44 & 5.25 \\
\hline & $5 \sim 6$ & 357 & 22.58 & 5.56 \\
\hline & $6 \sim 7$ & 237 & 24.41 & 6.87 \\
\hline & Total & 1029 & 21.45 & 6.16 \\
\hline \multirow{5}{*}{$\begin{array}{l}\text { Fundamental } \\
\text { movement } \\
\text { skills }\end{array}$} & $3 \sim 4$ & 104 & 35.22 & 8.54 \\
\hline & $4 \sim 5$ & 331 & 40.20 & 9.23 \\
\hline & $5 \sim 6$ & 357 & 46.23 & 9.22 \\
\hline & $6 \sim 7$ & 237 & 48.57 & 9.96 \\
\hline & Total & 1029 & 43.72 & 10.29 \\
\hline
\end{tabular}

\subsection{FMS Norms}

Based on the findings, we established norms for each age and gender group in locomotor skills, object control skills, and FMSs (see Tables 3, 4, 5 \& Figure 1,2,3). With a percentile rank of 50 , the four age groups were subdivided into eight age groups of six months each. For locomotor skills, the respective means for boys were $11,19,20,21,24$, 22,24 , and 24; and the respective means for girls were 15 , $18,18,21,24,24,24$, and 26. For object control skills, the respective means for boys were $15,18,19,21,24,23,25$, and 26; and the respective means for girls were $13,16,18$, 18, 20, 21, 22, and 23. For FMSs as a whole, the respective means for boys were $27,38,38,42,47,46,49$, and 49 ; and the respective means for girls were $29,35,37,39,43,45$, 44, and 47. 
Table 3. Locomotor skills norms

\begin{tabular}{|c|c|c|c|c|c|c|c|c|c|c|c|c|c|c|c|c|}
\hline \multirow{3}{*}{$\begin{array}{c}\text { percentile } \\
\text { rank }\end{array}$} & \multicolumn{16}{|c|}{ age } \\
\hline & \multicolumn{2}{|c|}{$\begin{array}{c}3-0 \\
\text { through } \\
3-5 \\
\end{array}$} & \multicolumn{2}{|c|}{$\begin{array}{c}\text { 3-6 } \\
\text { through } \\
3-11 \\
\end{array}$} & \multicolumn{2}{|c|}{$\begin{array}{c}\text { 4-0 } \\
\text { through } \\
4-5 \\
\end{array}$} & \multicolumn{2}{|c|}{$\begin{array}{c}\text { 4-6 } \\
\text { through } \\
4-11 \\
\end{array}$} & \multicolumn{2}{|c|}{$\begin{array}{c}5-0 \\
\text { through } \\
5-5\end{array}$} & \multicolumn{2}{|c|}{$\begin{array}{c}5-6 \\
\text { through } \\
5-11 \\
\end{array}$} & \multicolumn{2}{|c|}{$\begin{array}{c}6-0 \\
\text { through } \\
6-5 \\
\end{array}$} & \multicolumn{2}{|c|}{$\begin{array}{c}\text { 6-6 } \\
\text { through } \\
6-11 \\
\end{array}$} \\
\hline & M & $\mathrm{F}$ & $\mathrm{M}$ & $\mathrm{F}$ & M & $\mathrm{F}$ & M & $\mathrm{F}$ & M & $\mathrm{F}$ & M & $\mathrm{F}$ & $\mathrm{M}$ & $\mathrm{F}$ & M & $\mathrm{F}$ \\
\hline 1 & 1 & 9 & 7 & 7 & 10 & 11 & 11 & 9 & 4 & 13 & 13 & 10 & 11 & 13 & 14 & 15 \\
\hline 2 & 1 & 9 & 7 & 7 & 10 & 11 & 11 & 11 & 8 & 14 & 14 & 12 & 13 & 13 & 14 & 15 \\
\hline 5 & 1 & 9 & 11 & 9 & 12 & 12 & 12 & 13 & 15 & 15 & 16 & 16 & 16 & 15 & 15 & 15 \\
\hline 9 & 1 & 9 & 12 & 11 & 13 & 13 & 15 & 15 & 16 & 17 & 16 & 18 & 18 & 17 & 17 & 16 \\
\hline 16 & 5 & 9 & 13 & 13 & 14 & 14 & 16 & 17 & 18 & 19 & 18 & 19 & 20 & 19 & 18 & 18 \\
\hline 25 & 7 & 11 & 15 & 15 & 15 & 15 & 18 & 18 & 20 & 20 & 19 & 20 & 21 & 20 & 20 & 20 \\
\hline 37 & 7 & 12 & 16 & 17 & 16 & 17 & 20 & 20 & 21 & 22 & 21 & 23 & 22 & 22 & 22 & 24 \\
\hline 50 & 11 & 15 & 19 & 18 & 20 & 18 & 21 & 21 & 24 & 24 & 22 & 24 & 24 & 24 & 24 & 26 \\
\hline 63 & 15 & 19 & 20 & 19 & 21 & 19 & 23 & 23 & 26 & 25 & 24 & 26 & 26 & 26 & 26 & 27 \\
\hline 75 & 22 & 21 & 23 & 23 & 23 & 21 & 26 & 26 & 28 & 28 & 25 & 28 & 27 & 26 & 29 & 31 \\
\hline 84 & 27 & 21 & 24 & 25 & 26 & 23 & 30 & 28 & 30 & 29 & 27 & 29 & 28 & 29 & 32 & 33 \\
\hline 91 & & & 26 & 26 & 28 & 27 & 32 & 29 & 32 & 31 & 29 & 32 & 31 & 31 & 35 & 34 \\
\hline 95 & & & 27 & 31 & 31 & 28 & 33 & 32 & 36 & 33 & 34 & 34 & 33 & 34 & 37 & 36 \\
\hline 98 & & & 30 & & 33 & 30 & 36 & 34 & 37 & 35 & 36 & 39 & 36 & 40 & & \\
\hline 99 & & & & & & & & & & 39.5 & & & & & & \\
\hline
\end{tabular}

Table 4. Object control skills norms

\begin{tabular}{|c|c|c|c|c|c|c|c|c|c|c|c|c|c|c|c|c|}
\hline \multirow{3}{*}{$\begin{array}{c}\text { percentile } \\
\text { rank }\end{array}$} & \multicolumn{16}{|c|}{ age } \\
\hline & \multicolumn{2}{|c|}{$\begin{array}{c}3-0 \\
\text { through } \\
3-5\end{array}$} & \multicolumn{2}{|c|}{$\begin{array}{c}3-6 \\
\text { through } \\
3-11\end{array}$} & \multicolumn{2}{|c|}{$\begin{array}{c}\text { 4-0 } \\
\text { through } \\
4-5\end{array}$} & \multicolumn{2}{|c|}{$\begin{array}{c}\text { 4-6 } \\
\text { through } \\
4-11\end{array}$} & \multicolumn{2}{|c|}{$\begin{array}{c}5-0 \\
\text { through } \\
5-5\end{array}$} & \multicolumn{2}{|c|}{$\begin{array}{c}5-6 \\
\text { through } \\
5-11\end{array}$} & \multicolumn{2}{|c|}{$\begin{array}{c}6-0 \\
\text { through } \\
6-5\end{array}$} & \multicolumn{2}{|c|}{$\begin{array}{c}6-6 \\
\text { through } \\
6-11\end{array}$} \\
\hline & $\mathrm{M}$ & $\mathrm{F}$ & $\mathrm{M}$ & $\mathrm{F}$ & $\mathrm{M}$ & F & M & $\mathrm{F}$ & $\mathrm{M}$ & $\mathrm{F}$ & M & $\mathrm{F}$ & $\mathrm{M}$ & $\mathrm{F}$ & $\mathrm{M}$ & $\mathrm{F}$ \\
\hline 1 & 6 & 6 & 12 & 12 & 7 & 10 & 11 & 7 & 8 & 12 & 11 & 12 & 10 & 7 & 20 & 15 \\
\hline 2 & 6 & 6 & 12 & 12 & 8 & 10 & 11 & 8 & 11 & 12 & 13 & 12 & 11 & 8 & 20 & 15 \\
\hline 5 & 6 & 6 & 12 & 12 & 12 & 11 & 13 & 11 & 14 & 14 & 16 & 13 & 16 & 10 & 20 & 15 \\
\hline 9 & 6 & 6 & 13 & 13 & 14 & 12 & 14 & 12 & 16 & 15 & 18 & 14 & 17 & 13 & 21 & 16 \\
\hline 16 & 10 & 6 & 14 & 14 & 15 & 13 & 16 & 14 & 18 & 17 & 20 & 17 & 19 & 16 & 21 & 18 \\
\hline 25 & 12 & 8 & 15 & 15 & 16 & 14 & 17 & 15 & 20 & 17 & 21 & 18 & 21 & 18 & 22 & 18 \\
\hline 37 & 13 & 12 & 17 & 15 & 18 & 16 & 19 & 16 & 22 & 19 & 22 & 20 & 24 & 20 & 24 & 21 \\
\hline 50 & 15 & 13 & 18 & 16 & 19 & 18 & 21 & 18 & 24 & 20 & 23 & 21 & 25 & 22 & 26 & 23 \\
\hline 63 & 15 & 14 & 19 & 19 & 21 & 20 & 22 & 21 & 26 & 22 & 25 & 23 & 28 & 24 & 29 & 27 \\
\hline 75 & 17 & 16 & 20 & 20 & 22 & 22 & 24 & 22 & 28 & 24 & 27 & 25 & 29 & 26 & 33 & 31 \\
\hline 84 & 19 & 18 & 22 & 21 & 24 & 23 & 26 & 24 & 30 & 26 & 30 & 27 & 32 & 29 & 37 & 33 \\
\hline 91 & & & 24 & 23 & 27 & 25 & 29 & 26 & 33 & 28 & 33 & 30 & 34 & 32 & 39 & 35 \\
\hline 95 & & & 27 & 27 & 29 & 27 & 33 & 27 & 35 & 29 & 36 & 32 & 40 & 35 & 41 & 38 \\
\hline 98 & & & 32 & & 32 & 28 & 36 & 31 & 38 & 33 & 38 & 34 & 42 & 37 & & \\
\hline 99 & & & & & & & & & & 35 & & & & & & \\
\hline
\end{tabular}


Table 5. FMS norms

\begin{tabular}{|c|c|c|c|c|c|c|c|c|c|c|c|c|c|c|c|c|}
\hline \multirow{3}{*}{$\begin{array}{c}\text { percentile rank } \\
\text { gender }\end{array}$} & \multicolumn{16}{|c|}{ age } \\
\hline & \multicolumn{2}{|c|}{$\begin{array}{c}3-0 \\
\text { through } \\
3-5\end{array}$} & \multicolumn{2}{|c|}{$\begin{array}{c}3-6 \\
\text { through } \\
3-11\end{array}$} & \multicolumn{2}{|c|}{$\begin{array}{c}4-0 \\
\text { through } \\
4-5\end{array}$} & \multicolumn{2}{|c|}{$\begin{array}{c}4-6 \\
\text { through } \\
4-11\end{array}$} & \multicolumn{2}{|c|}{$\begin{array}{c}5-0 \\
\text { through } \\
5-5\end{array}$} & \multicolumn{2}{|c|}{$\begin{array}{c}5-6 \\
\text { through } \\
5-11\end{array}$} & \multicolumn{2}{|c|}{$\begin{array}{c}6-0 \\
\text { through } \\
6-5\end{array}$} & \multicolumn{2}{|c|}{$\begin{array}{c}6-6 \\
\text { through } \\
6-11\end{array}$} \\
\hline & $\mathrm{M}$ & $\mathrm{F}$ & $\mathrm{M}$ & $\mathrm{F}$ & $\mathrm{M}$ & $\mathrm{F}$ & M & $\mathrm{F}$ & $\mathrm{M}$ & $\mathrm{F}$ & M & $\mathrm{F}$ & $\mathrm{M}$ & $\mathrm{F}$ & M & $\mathrm{F}$ \\
\hline 1 & 13 & 16 & 22 & 22 & 18 & 23 & 25 & 21 & 12 & 25 & 30 & 28 & 29 & 26 & 39 & 33 \\
\hline 2 & 13 & 16 & 22 & 22 & 19 & 23 & 25 & 25 & 21 & 28 & 32 & 29 & 32 & 27 & 39 & 33 \\
\hline 5 & 13 & 16 & 24 & 25 & 27 & 24 & 28 & 29 & 32 & 33 & 35 & 32 & 35 & 30 & 40 & 33 \\
\hline 9 & 13 & 16 & 26 & 26 & 28 & 25 & 30 & 30 & 35 & 35 & 38 & 33 & 37 & 35 & 42 & 35 \\
\hline 16 & 13 & 20 & 28 & 30 & 30 & 28 & 33 & 32 & 38 & 37 & 39 & 37 & 40 & 38 & 43 & 36 \\
\hline 25 & 18 & 25 & 31 & 31 & 33 & 31 & 36 & 35 & 41 & 39 & 41 & 39 & 43 & 41 & 45 & 40 \\
\hline 37 & 22 & 26 & 34 & 33 & 35 & 34 & 40 & 37 & 44 & 41 & 43 & 43 & 47 & 43 & 46 & 45 \\
\hline 50 & 27 & 29 & 38 & 35 & 38 & 37 & 42 & 39 & 47 & 43 & 46 & 45 & 49 & 44 & 49 & 47 \\
\hline 63 & 32 & 32 & 39 & 37 & 42 & 39 & 46 & 43 & 51 & 46 & 48 & 49 & 52 & 48 & 52 & 55 \\
\hline 75 & 36 & 32 & 43 & 41 & 45 & 42 & 49 & 45 & 56 & 50 & 52 & 51 & 56 & 51 & 59 & 61 \\
\hline 84 & 44 & 32 & 45 & 43 & 49 & 44 & 51 & 49 & 60 & 54 & 57 & 55 & 59 & 56 & 65 & 63 \\
\hline 91 & & & 46 & 50 & 52 & 48 & 57 & 53 & 62 & 57 & 59 & 61 & 65 & 61 & 70 & 69 \\
\hline 95 & & & 49 & 53 & 54 & 49 & 64 & 57 & 65 & 60 & 63 & 64 & 66 & 65 & 76 & 74 \\
\hline 98 & & & 58 & & 63 & 52 & 70 & 60 & 70 & 67 & 69 & 73 & 71 & 73 & & \\
\hline 99 & & & & & & & & & & 74 & & & & & & \\
\hline
\end{tabular}

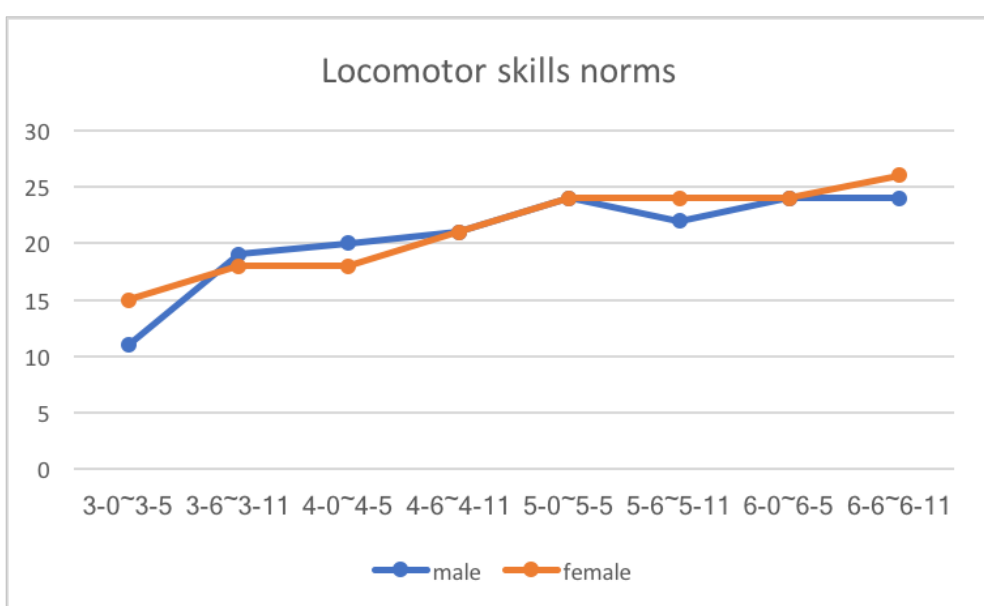

Figure 1. Locomotor skills norms

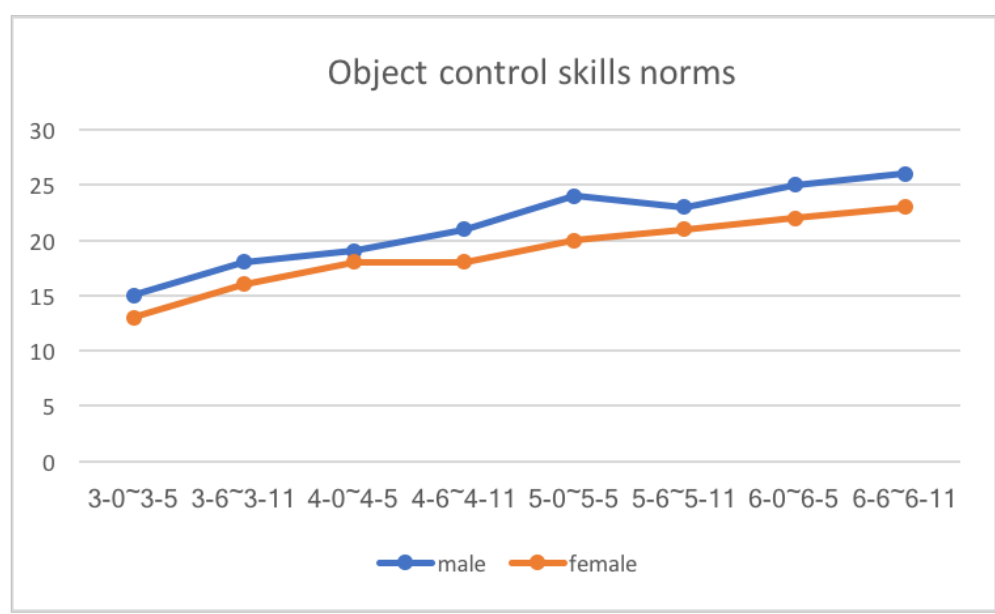

Figure 2. Object control skills norms 


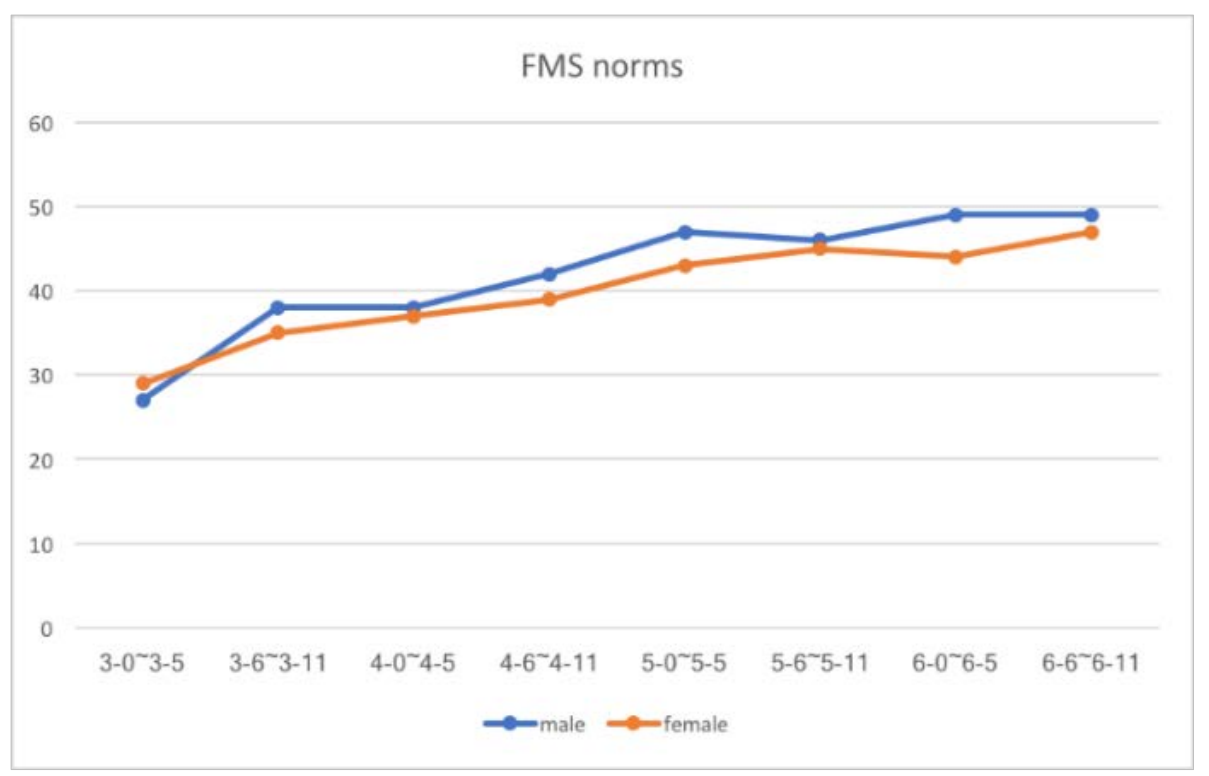

Figure 3. FMS norms

\section{Discussion}

With a percentile rank of 50, in most of the age groups the mean score in locomotor skills for the boys was higher than that for the girls, but in three age groups (3-31/2, 51/26 , and $6 \frac{1}{2}-7$ ) the opposite was the case. By contrast, Ulrich and Sanford [12] found no differences between boys and girls for this item. Also, with a percentile rank of 50, when comparing the participants in the present study with their American counterparts, we found that in each age group the Taiwanese children had lower scores in locomotor skills, and the higher the age group, the larger the difference. This is a significant finding requiring further investigation.

As for object control skills, at the percentile rank of 50, in all the age groups the mean score for the boys was higher than that for the girls, as was also found by Ulrich and Sanford [12]. It was also found in both studies that the difference becomes more marked from the age of 5 onwards. The data reveals that in this skill Taiwanese preschoolers lag behind their American counterparts by one or two years; the reasons for this discrepancy requires further investigation.

The three related studies conducted in Taiwan using TGMD-2 mentioned above also found that Taiwanese preschoolers lag behind their American counterparts in both locomotor and object control skills, and this discrepancy needs to be given due attention by the relevant educational authorities in Taiwan [21-23].

The relatively low performance in FMSs by Taiwanese preschoolers needs to be addressed on three levels: parents, schools, and teachers. As for parents, according to a report by the Child Welfare League Foundation, many Taiwanese children don't get sufficient exercise, mainly due to poor air quality, parents' lack of time, lack of suitable facilities, and safety concerns [26]. Similarly, Fjortoft, Pedersen, Sigmundsson, and Vereijken assert that due to the prevalence of automobiles, these days few children walk or bike to school [27] and that for both parents and children physical and outdoor activity is increasingly being replaced by less physical indoor activities such as internet browsing, playing video games, and watching television [28]. As for schools, even though preschools typically schedule 30 minutes per day of rigorous exercise, for many teachers this means any physical activity whatsoever, such as playing tag or playing with musical toys [29]. Also, the differences between preschools in terms of PE facilities can be large. Some provide mainly sensory integration toys; for inside play, some have only large inflated balls for bouncing on; and for outside play, some only have bicycles, four-wheelers, etc.; many don't organize ball games.

As for preschool teachers, most are women with little or no training in FMS education. Even if they do have some FMS background, the preschool might not provide the required equipment and facilities to make use of it. Also, preschools tend to give more importance to classroom learning, and presently PE at most preschools in Taiwan consists of little more than simple rhythmic exercises and a freeform playground session after school. Another reason for this dearth of FMS training is that few preschool teachers have sufficient time to organize various ball games. There may be additional reasons for the relatively low performance in FMSs by Taiwanese preschoolers, and this is a topic requiring further investigation.

For the four age groups aged $3-7$, the mean scores in locomotor skills ranged from 18.00 to 24.17 ; the mean scores in object control skills ranged from 17.22 to 24.41; and the mean scores for overall FMSs ranged from 35.22 to 48.57.

With a percentile rank of 50 , in most of the eight age 
groups, the mean scores in locomotor skills for the boys were higher than that for the girls, but in three age groups (3-31/2, 51/2-6, and 61/2-7) the opposite was the case. As for object control skills, at the percentile rank of 50, in all the age groups the mean scores for the boys were higher than that for the girls. As for overall FMSs, at the percentile rank of 50, in seven of the eight age groups the mean scores for the boys were higher than that for the girls, but the girls' mean score was higher in the youngest age group (3-31/2).

\section{Conclusions}

Based on the findings of this study, we suggest that parents and schools give more attention to preschoolers' development of FMSs. Parents could make more use of their free time to play ball games with their children and to introduce them to various outdoor activities; parents would also do well to encourage their children to make less use of consumer electronics which encourage a sedentary lifestyle, for which purpose setting a personal example is essential. As for preschools, we suggest that they provide more equipment and facilities for encouraging preschoolers of different ages to engage in physical play, especially ball games. They should also allot between 30 and 60 minutes daily for vigorous exercise and have teachers trained in conducting various types of non-competitive ball games, of the type which are fun and easy. Also, teachers should make efforts to ensure that boys and girls are developing equally in terms of movement skills, encouraging girls to participate in ball games, while providing adequate guidance and supervision so as to minimize injuries. As for the university, the curriculum of preschool teachers' training should incorporate FMS into the PE course. Implementing these suggestions will go a long way in enhancing preschoolers' FMSs, as well as their development in terms of social skills, intellectual ability, and emotional maturity.

\section{REFERENCES}

[1] John, J., Ratey, M. D., \& Eric, H. (2015). Spark: The revolutionary new science of exercise and the brain. (Hsieh, W. L.Trans.). Taipei: Ye Ren Wen Hua. (Original work published 2008).

[2] Strong, W. B., Malina, R. M., Blimkie, C. J. R., Daniels, S. R., Dishman, R. K., Gutin, B., Trudeau, F. (2005). Evidence basedphysical activity for school-age youth. The Journal of Pediatrics, 146(6), 732-737.

[3] Shields, M. (2006). Overweight and obesity among children and youth. Health Reports, 17(3), 27-42.

[4] Bouchard, C., Blair, S.N., \& Haskell, W. L. (2007). Physical activity and health. Champaign, IL: Human Kinetics.
[5] Cliff, D. P. (2008). Promoting physical activity among overweight and obese children: A randomized controlled trial comparing a physical activity program, a dietary program and a combined physical activity plus dietary program (Unpublished doctoral dissertation). University of Wollongong, New South Wales, Australia.

[6] D'Hondt, E., Deforche, B., Bourdeaudhuij, I. D., \& Lenoir, M. (2009). Relationship between motor skill and body mass index in 5-to 10-year-old children. Adapted Physical Activity Quarterly, 26 (1), 21-37.

[7] Williams, H. G., Pfeiffer, K. A., O'Neill, J. R., Dowda, M., Mclver, K. L., Brown, W. H., \& Pate, R. R. (2008). Motor skill performance and physical activity in preschool children. Obseity, 16(6), 1421-1426.

[8] Fisher, A., Reilly, J. J., Kelly, L. A., Montgomery, C., Williamson, A., Paton, J. Y., \& Grant, S. (2005). Fundamental movement skills and habitual physical activity in young children. Medicine and Science in Sports and Exercise, 37(4), 684-688.

[9] Clark, J. E. (2007). On the problem of motor skill development. Journal of Physical Education, Recreation and Dance, 78(5), 39-44.

[10] Hardy, L. L., King, L., Farrell, L., Macniven, R., \& Howlett, S. (2010). Fundamental movement skills among Australiam preschool children. Journal of Science and Medicine in Sport, 13(5), 503-508.

[11] Huang, H. C., Chou, C. C., Cheng, C. Y., \& Lin, C. W. (2005). The impact of intervention of a motor skills program on preschool children's fundamental motor skills and cognition of movement concept. Research Quarterly for Exercise and Sport, 76(1), A77-A78.

[12] Ulrich, D. A., \& Sanford, C. B. (2000). Test of gross motor development: Examiner's manual (2nd ed.). Austin TX: Proed.

[13] Logan, S. W., Robinson, L. E., Wilson, A. E., \& Lucas, W. A. (2012). Getting the fundamentals of movement: a meta-analysis of the effectiveness of motor skill interventions in children. Child: Care, Health and Development, 38(3), 305-315.

[14] Pang, A. W. Y., \& Fong, D. T. P. (2009). Fundamental motor skill proficiency of Hong Kong children aged 6-9 years. Research in Sports Medicine, 17(3), 125-144.

[15] Sun, S. H., Zhu, Y. C., Shih, C. L., Lin, C. H., \& Wu, S. K. (2010). Development and initial validation of the preschooler gross motor quality scale. Research in Developmental Disabilities, 31(6), 1187-1196.

[16] Robinson, L. E., \& Goodway, J. D. (2009). Instructional climates in preschool children who are at-risk. Part I: Object-control skill development. Research Quarterly for Exercise and Sport, 80(3), 533-542.

[17] Zeng, N., Johnson, S. L., Boles, R. E., \& Bellows, L. L. (2019). Social-ecological correlates of fundamental movement skills in young children. Journal of Sport and Health Science, 8, 122-129.

[18] Wrotnik, B. H., Epstein, L. H., Dorn, J. M., Jones, K. E., \& Kondilis, V. A. (2006). The relationship between motor proficiency and physical activity in children. Pediatrics, 
118(6), E1758-E1765.

[19] Oliver, M., Schofield, G., \& McEvoy, E. (2006). An integrated curriculum approach to increasing habitual physical activity in children: a feasibility study. Journal of School Health, 76(2), 74-79.

[20] Wang, T. T. (2013). Implementation strategy of physical movements and health domain, based on the new kindergarten curriculum guidelines. Sports Research Review, $126,15-22$.

[21] Lin, S. J. (2014). Study on the development of three to nine-year-old children's fundamental movement skills and norms construction in Chiayi Area (Unpublished doctoral dissertation). National Chiayi University, Chiayi City.

[22] Wang, C. Y. (2004). Establishing the norm of TGMD-2 locomotor subtest: A norm of the fourth graders in Taoyuan County Jhuniheng Elementary School (Unpublished master's thesis). National Taipei Teachers College, Taipei.

[23] Chen, T. C. (2004). Establishing the norm for TGMD-2 object control subtest: Changhua County Caohu Elementary School students (Unpublished master's thesis). National Taipei Teachers College, Taipei.

[24] Health Promotion Administration, Ministry of Health and Welfare (2018). Recommended body mass index (BMI) for children and adolescents. Retrieved from https://www.hpa.gov.tw/

Pages/Detail.aspx?nodeid=542\&pid=9547

[25] Wong, K. Y., \& Cheung, S. Y. (2010). Confirmatory factor analysis of the test of gross motor development-2. Measurement in Physical Education and Exercise Science, 14(3), 202-209.

[26] Child Welfare League Foundation (2018, March 22). 2018 children's sports survey report. Retrieved from https://www.children.org.tw/research/detail/70/1350

[27] Fjortoft, I., Pedersen, A.V., Sigmundsson, H., \& Vereijken, B. (2011). Measuring physical fitness in children who are 5 to 12 years old with a test battery that is functional and easy to administer. Physical Therapy, 91(7), 1087-1095.

[28] Lindsay, A. C., Arruda, C. A. M., De Andrade, G. P., Machado, M. M. T., \& Greaney, M. L. (2019). Parenting practices that may encourage and discourage physical activity in preschool-age children of Brazilian immigrant families: A qualitative study. Plos One, 14(3), 1-18.

[29] Shu, M. J., \& Huang, Y. K. (2015). A Study of the Implementation of Thirty Minute Gross Motor Activities in a Public Kindergarten. Journal of Early Childhood Education \& Care, 14, 1-18. 